\title{
Tonometry and tonography in the diagnosis of chronic simple glaucoma
}

\author{
D. CAMERON, E. T. FINLAY, AND C. R. S. JAGKSON \\ From the Eye Department, Royal Infirmary, Edinburgh
}

Tonometry has long been considered a satisfactory and accurate aid to the diagnosis of chronic simple glaucoma and, since the publication of a paper by Grant (1950), tonography has been acclaimed as a useful additional refinement. The results of tonography have $\frac{0}{0}$. been expressed either alone as an indicator of facility of aqueous outflow $(\mathbf{G})$ or combineder with a measure of intraocular pressure $(\mathrm{Po})$ and expressed as $\mathrm{Po} / \mathrm{C}$, the coefficient of outflow.

Many of the observers who have confirmed Grant's findings have failed to state clearlyo their criteria for the diagnosis of chronic simple glaucoma. For example, Tuovinen? ( I96 I) implied that the diagnosis was, in part, based on tonometry and tonography, sothat his argument about the effectiveness of the tests depends on the prior assumptiono that the tests are effective.

We will show that confidence in the results of tonometry and tonography is misplaced, especially in those reports in the literature, for example Paterson (1966), where these measurements taken at certain levels are accepted as diagnostic of chronic simple glaucong $\stackrel{\bullet}{=}$

Previous studies of tonography should have warned us against this practice. Gloser: (1966) found that in 108 normal eyes all exceeded 0.12 in $\mathrm{C}$ value, and only 4 per cent. had values lower than 0.15 . His experience in thirty glaucomatous eyes showed that the tests were less discriminating. $\mathrm{C}$ values were higher than 0.12 in 73 per cent. ando higher than $0 \cdot 15$ in 54 per cent.

In our study we have made tonometric and tonographic observations and calculated the coefficient of outflow in four groups of eyes: non-glaucomatous, 'suspicious', untreated glaucoma, and treated glaucoma.

\section{Criteria for diagnosis}

CHRONIC SIMPLE GLAUCOMA

(I) Cupping of the optic disc

and (2) Visual field loss of a glaucomatous type

and (3) An open anterior chamber angle

We should regard an eye as 'suspicious' if it showed:

( I) Cupping of the optic disc

or (2) Visual field loss of a glaucomatous type

or (3) The fellow eye was glaucomatous

In no case has our diagnosis depended on a numerical value of tension or outflow. We have relied on clinical methods, including ophthalmoscopy, gonioscopy, and detailed 
examination of the visual fields. This latter test was carried out at 2 metres distance, normally with a $2 \mathrm{~mm}$. white object or with the smallest target which permitted the patient to give accurate and reproducible replies.

The number of eyes examined was 855 , in $45^{\mathrm{I}}$ individuals.

\section{Results}

Table I shows that the means of all our observations fall neatly into place.

Table I Means of $P o, C$ value, and $P o / C$ in four groups of eyes

\begin{tabular}{|c|c|c|c|c|}
\hline Group & $\begin{array}{l}\text { No. of } \\
\text { eyes }\end{array}$ & $P o$ & $C$ value & $\mathrm{Po} / \mathrm{C}$ \\
\hline Nonglaucomatous & 617 & $17.7 \pm 0.17$ & $0.28 \pm \cdot 005$ & $83 \cdot 2 \pm 2 \cdot 5$ \\
\hline 'Suspicious' & 95 & $20.7 \pm 0.56$ & $0.20 \pm .011$ & $153.4 \pm 13.2$ \\
\hline Glaucoma Untreated & 49 & $23 \cdot 2 \pm 1 \cdot 07$ & $0 \cdot 18 \pm \cdot 016$ & $165 \cdot 4 \pm 21 \cdot 9$ \\
\hline Treated & 95 & $21 \cdot 8 \pm 1 \cdot 27$ & $0.19 \pm 0.23$ & $163.2 \pm 17.5$ \\
\hline
\end{tabular}

The results in the four groups of eyes show a relationship to each other that we should expect from the propositions that glaucomatous eyes have higher intraocular tensions and lower outflow facilities and coefficients of outflow than do normal eyes.

The eyes in our 'suspicious' group are intermediate between the non-glaucomatous eyes and the glaucomatous eyes, and the glaucomatous eyes under treatment show a tendency towards normality.

All this is well known. Some of the differences are not very great and of course refer only to the large groups of eyes which were examined. The danger of arguing from the means of these groups to individuals will be seen from the rest of the results.

Table II shows a summary of the measures of intraocular pressure at two levels of $P_{0}$ which have been traditionally used to discriminate between non-glaucomatous and glaucomatous eyes. It will be seen that although there are large and statistically significant differences between these two groups of eyes, neither level discriminates so sharply that, from Po value alone, could an eye be allotted to one group or another. In the case of the glaucomatous eyes the distinguishing power is so poor that all the eyes would have to be examined by ophthalmological means.

Table II Distribution of intraocular pressure $(P o)$ in four groups of eyes, above two threshold levels

\begin{tabular}{|c|c|c|c|}
\hline \multirow{2}{*}{ Group } & \multirow{2}{*}{$\begin{array}{l}\text { No. of } \\
\text { eyes }\end{array}$} & \multicolumn{2}{|l|}{ Po } \\
\hline & & $>21$ & $>24$ \\
\hline Nonglaucomatous & 617 & $134(21 \cdot 7$ per cent. $)$ & $5^{2}(8 \cdot 4$ per cent.) \\
\hline 'Suspicious' & 95 & $45(47 \cdot 4$ per cent. $)$ & 32 (33.7 per cent.) \\
\hline Glaucoma Untreated & 49 & $30(6 \mathrm{I} \cdot 2$ per cent.) & 19 (38.8 per cent.) \\
\hline Treated & 95 & $59(62 \cdot 1$ per cent. $)$ & $4^{2}$ (44.2 per cent.) \\
\hline
\end{tabular}


Table III shows a summary of measures of outflow facility at three levels which have commonly been considered to be significant. A G value of less than 0.12 is very unlikel to be found in a normal eye, but it is not very likely to be found in a glaucomatous ey $\overline{\bar{g}}$ either. Again, in spite of the differences between the means of the groups, $\mathrm{G}$ value does. not distinguish clearly between individual glaucomatous and normal eyes.

Table III Facility of outflow $(C)$ in four groups of eyes, below three threshold levels

\begin{tabular}{|c|c|c|c|c|}
\hline \multirow{2}{*}{ Group } & \multirow{2}{*}{$\begin{array}{l}\text { No. of } \\
\text { eyes }\end{array}$} & \multicolumn{3}{|l|}{$C$ value } \\
\hline & & $<\cdot 12$ & $<\cdot 15$ & $<\cdot 20$ \\
\hline Nonglaucomatous & 617 & $34(5.5$ per cent. $)$ & $\overline{6_{4}}(\overline{10 \cdot 4 \text { per cent. })}$ & I66 (26.9 per cent ${ }^{\circ}$ \\
\hline 'Suspicious' & 95 & 19 (20.0 per cent.) & $3^{1} \quad\left(3^{2} \cdot 6\right.$ per cent. $)$ & $50 \quad(52.6$ per cent $\stackrel{\text {. }}{ }$ \\
\hline Glaucoma Untreated & 49 & $6(12 \cdot 2$ per cent. $)$ & 19 $(38.8$ per cent.) & 35 (7I 4 per cent $\Phi$ \\
\hline Treated & 95 & $25(26 \cdot 3$ per cent. $)$ & $46(48 \cdot 4$ per cent. $)$ & $61 \quad(64 \cdot 2$ per cent.9 \\
\hline
\end{tabular}

Table IV shows a summary of coefficients of outflow at two different levels. This inde gives us no great power to discriminate glaucoma from non-glaucoma than do the other. two.

Table IV Coefficient of outflow $(P o / C)$ in four groups of eyes, above two threshold levels

\begin{tabular}{|c|c|c|c|}
\hline \multirow{2}{*}{ Group } & \multirow{2}{*}{$\begin{array}{l}\text { No. of } \\
\text { eyes }\end{array}$} & \multicolumn{2}{|l|}{$\mathrm{Po} / \mathrm{C}$} \\
\hline & & $>100$ & $>150$ \\
\hline Nonglaucomatous & 617 & I 73 (28.o per cent.) & 69 (II $\cdot 2$ per cent. $)$ \\
\hline 'Suspicious' & 95 & $54(56 \cdot 8$ per cent. $)$ & 35 (36.8 per cent.) \\
\hline Glaucoma Untreated & 49 & $37(75.5$ per cent. $)$ & 20 (40.I per cent.) \\
\hline Treated & 95 & $62(65.2$ per cent. $)$ & $50(52 \cdot 6$ per cent. $)$ \\
\hline
\end{tabular}

\section{Discussion}

We have shown that, using generally accepted critical levels of tonometry and tonography there is so much overlap of measurements that these tests are rendered useless as aids ti diagnosis of chronic simple glaucoma in individual cases. It is obvious that there i serious danger in using either of these tests alone, or in using the two combined. The number of false negatives means that many patients with clinical glaucoma will be le untreated, and the number of false positives means that many who have normally funct ioning eyes, will be subjected to unnecessary treatment.

We have applied the numerical diagnostic criteria of Paterson (1965) (a pressure of over $25 \mathrm{~mm}$. $\mathrm{Hg}$ on the applanation tonometer and a reduced outflow value- $\mathrm{Po} / \mathbb{W}_{\mathrm{W}}$ greater than 100) to our non-glaucomatous eyes and our 'suspicious' eyes. We founds in the non-glaucomatous group, that this would reclassify 33 of them as glaucomatouso In the 'suspicious' group, it would reclassify 25 of them as glaucomatous. Only one of these $5^{8}$ patients had any sign of field defect. 
Even as screening tests, these procedures are highly unsatisfactory. There is no critical level in these tests which would not result in the referral of an intolerable number of false positive cases for ophthalmological examination and none that would not allow an unacceptable number of patients with untreated glaucoma to be sent home in the belief that their eyes were healthy.

Fig. I shows the distribution of $\mathrm{C}$ values in our cases with its large overlap rendering the test insufficiently discriminating. Alongside is an ideal distribution showing a hypothetical test in which discrimination is good (Fig. 2).

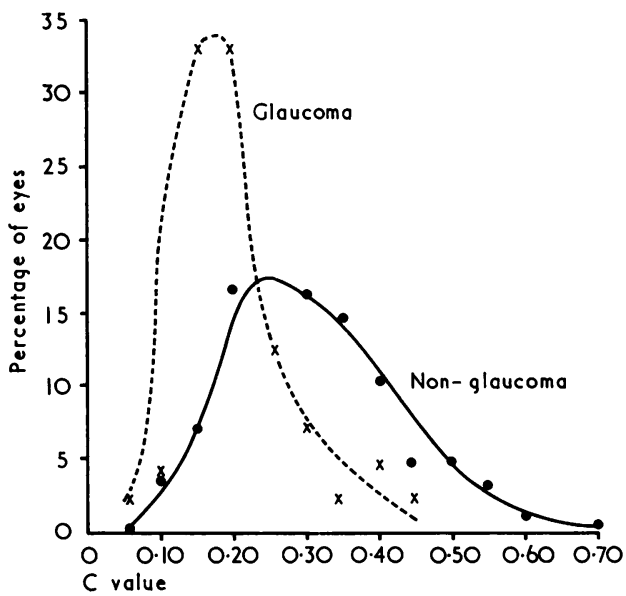

F I G. I Distribution of $C$ values in glaucomatous and non-glaucomatous eyes

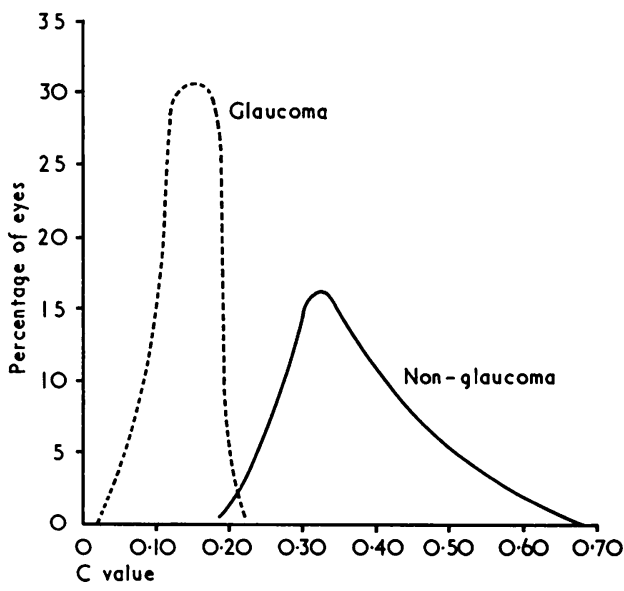

FIG. 2 Hypothetical distribution of $C$ values to allow good discrimination

We believe we have shown that tonometry and tonography unsupported by full clinical ophthalmological examination cannot be used for the diagnosis or the elimination of chronic simple glaucoma. It is not our intention to comment here on the usefulness or otherwise of these tests in the assessment of the progress of the disease or of the results of treatment.

\section{References}

GLOSTER, J. (1966) "Tonometry and Tonography". Churchill, London GRANT, W. M. (1950) Arch. Ophthal. (Chicago), 44, 204

PATERSON, G. D. (1966) "The value of family studies in the detection of glaucoma simplex", in

"Glaucoma: Proceedings of a Symposium, 1965", ed. L. B. Hunt, p. 51. Livingstone, Edinburgh TUOvinen, E. (1961) Acta ophthal. (Kbh.), 39, Suppl. 67 